\title{
Transverse Vibration of Cracked Graded Rayleigh Beam with Axial Motion
}

\author{
Nabaa A. Bachay ${ }^{\text {a }}$, Talib Eh. Elaikh ${ }^{\text {b }}$ \\ a,b Mechanical Engineering Department, Thi-Qar University, Iraq, \\ Corresponding author email. alnabaa1996alnabaa@gmail.com.
}

\begin{abstract}
The paper presents the transverse vibration of an open edge crack graded Rayleigh beam with axial motion. The vibration equation was obtained relying on Hamilton's precept and resolved by the approach of Galerkin's. The powerlaw is adopted to represent the gradient of properties of the material composing the beam along the direction of the thickness. Cracks were modeled as rotational massless spring. The effects of axial velocity, material property change index, location, and depth of cracking on the vibration characteristics are observed. Also, the corresponding mode shapes are found for cracked moving graded Rayleigh beam with simply supported, and fixed-fixed end supports. The results clear up that the natural frequencies drop due to the rise in the axial velocity, the crack depth, and the material property index.
\end{abstract}

Keywords: Free Vibration, Functionally Graded Material, Axially Moving, Beam, Crack

\section{Introduction}

Because of the technical significance of the axial movement of engineering structures, as it is used in many mechanical, civil, and electronic engineering applications, such as power transmission belts, fluid transfer tubes, etc. [1], several studies have discussed the axial motion of the beam using different beam theories, as well as several solution methods as, J. R. Chang et al. [2] to solve the axially moving equations of a homogeneous beam derived based on of Rayleigh beam theory and Hamilton precept, the approach of a finite element has relied upon. Through the results, it was found that the decrease in the amplitude of the axial oscillation of the beam leads to a reduction of the unstable areas in the system.

According to Timoshenko's theory and Hamilton's extended, Y. Yesilce [3] derived the kinematic equations for a moving homogeneous beam with pinned-pinned, fixed and cantilever end supports. The method of differential transformation has been adopted to solve the vibration equations. The results showed that the axial tensile load is significant because it directly affects the natural frequencies (the frequencies rise with the augmentation in the axial tensile load or decrease with its decrease).

H. Y. Chen and H. B. Chen [4] demonstrate the influence of the axial compression load on a homogeneous beam moving axially. They relied on Timoshenko's theory to derive the vibration equations as they solved using Galerkin and differential quadrature methods. The effect of some factors on frequencies, including movement speed and compressive load factor was discussed. The results showed that the critical velocity decreases as a result of increased compression load and vice versa, and their combination (i.e. the axial velocity and the compression load together) leads to regression in beam stability. N. Liu et al. [5], using Bernoulli Euler theorem and the second law of Newton, the vibration equation for a beam moving axially under the action of the lumped mass derived and this equation solved using Galerkin's method. The results indicated that increasing the axial speed and weight of lumped mass reduces the natural frequencies. Z. Yang et al. [6] used differential quadrature and the Galerkin methods to find natural frequencies from the kinematic equations of the axially moving homogeneous Timoshenko beam for clamped end condition. R. F. Zinati et al. [7] found the foundations of the governing equation for a nonlinear, moving, flexible, viscous beam with intermediate support using Rayleigh's model and Hamilton's principle. Through results, rotational inertia was found to lead to a significant decrease in natural frequencies, while the rise in natural frequencies was dominated by the medium support of the beam.

The vibration of moving beam with free, simply assisted, clamped end conditions were explained by $\mathbf{H}$. Ding et al. [8], The approach of dynamic stiffness was used to solve the derived motion equations depending on the Euler and Timoshenko models.

M. Avcar [9] established the motion equation of a homogeneous beam for clamped, simply supported, clamped-simply supported, and cantilever end supported based on the Euler model and solved by the Newton Raphson method.

Due to the existence of advanced engineering applications that require a material with certain characteristics to withstand the working conditions, and 
these properties may sometimes be contradictory, meaning that they cannot be contained in the single homogeneous material used. Therefore, sometimes we need to combine two materials to obtain a substance that has properties that differ from the basic properties of its constituent materials. A new type of composite material in which properties are continuously and smoothly graduated from one substance to another to avoid the problem of deformation in armored vehicles, and which was first used by a group of Japanese scientists during a spaceplane project in 1984, is known as a functionally graded material (FGM). These materials have become popular in many applications recently, such as airframes, vibrating engine casings, human implants [10], thermal barrier systems, bamboo, teeth [11], nuclear reactors, biomedical, and electronics [12]. FGM is usually a mixture of ceramics and metals. M. Avcar [13] the vibration equation of the inhomogeneous Rayleigh beam was addressed. The differences in the material property gradient have followed the power-law distribution to represent it.

S.A. Sina et al. [14], used the shear deformation model to establish the functionally graded beam vibration equation for cantilever, simply support and clamped end conditions which were solved by an analytic method. Discussed the influence of shear deformation factor and material gradient indicator on vibration characteristics .

Zhao and Wang [15], Hamilton's precept and Euler model were relied to establish the vibration equation of a functionally graded beam with cantilever end condition. By count on the power-law, the material properties differ by the thickness direction. To solve the vibration equation, the Galerkin method was used. The impacts on natural frequencies of the gradient index of the material properties and speed of deployment were studied.

Aydogdu and Taskin [16], Shear deformation and Euler-Bernoulli models were used to find the vibration equations of the pinned-pinned graded beam. The properties of functionally graded material varied according to exponential and power laws through the thickness direction. The vibration equations were resolved by the Navier type solution.

H. T. Thai and T. P.Vo [17], the vibration of a graded beam was developed using shear deformation theorem. The properties of material varied along the beam thickness direction relying on power-law. The results showed the gradient index of the material properties and the shear deformation factor adversely affect the natural frequencies (i.e. the frequencies decrease by increasing both the material properties gradient factor and the shear deformation factor).

M. Simsek [18], the buckling of the functionally graded material was addressed according to the Timoshenko model. The material properties followed the law of power to vary through two directions as thickness and axial. The impacts of the shear deformation and the regression index of material properties on the buckling were investigated.
M. H. Ghayesh [19] used Galerkin's method to solve the equation of viscoelastic imperfect functionally graded microbeam that was derived according to Hamilton's principle and Timoshenko model .

A. E. Alshorbagy et al. [20], the Euler vibration equation of the graded beam has solved using the Galerkin approach, the material followed the form of power-law to alter via its properties through directions of thickness and axial.

H. Deng and W. Cheng [21] studied the dynamic behavior of a non-homogenous beam. The properties of a material graded functionally change in two dimensions, e.g. thickness and axial by count on the exponential law. The kinematic equations for this system relied on the Timoshenko theory and Hamilton's precept. The result shows that the axial gradient indicator affects the first frequency depending on the boundary conditions, while the thickness gradient indicator affects the first frequency inversely (i.e. the frequency increases with the decrease of the gradient indicator and vice versa).

In addition, there are several studies dealing with the study of the cracked graded beam as, Y. Liu et al. [22] clarified the impact of the single delamination on the graded beam that alters exponentially in the direction of thickness. To resolve the equation of motion, an analytical solution has been relied upon. The reduction in the elasticity ratio module causes a drop in natural frequencies.

T. Van Lien et al. [23] studied the vibration of a graded beam exposed to multiple cracks. They adopted Timoshenko's theorem and Hamilton's principle as the basis for deriving the kinematic equations for this system. They used the dynamic stiffness method to resolve these equations and find natural frequencies. They studied the influence of many factors on natural frequencies, including gradient power index, beam length to beam height ratio, elastic modulus ratio, the location of the crack, and the depth of the crack.

A. Banerjee et al. [24] observed the vibration of a cracked graded beam. The Timoshenko theory was adopted to develop the vibration equation that solved utilizing frequency contour and the model of response surface with a genetic algorithm. The properties of graded material altered during the beam thickness by count on the exponential law.

S. Kitipornchai et al. [25], Timoshenko's model was adopted to analyze the buckling non-homogeneous beam exposed to crack. The drop in the depth of a crack causes the rise in natural frequencies and a load of buckling.

As well as, A. S. J. Swamidas et al. [26] demonstrated the effect of cracking on the homogeneous beam. The kinematic equations were formulated using Euler and Timoshenko models and disband these equations using the Galerkin approach. The results revealed the cracking effect on the beam is equal in both models when the ratio of the beam length to its height is greater than 10 . When the ratio of the 
length of the beam to its height is less than 10 , the Timoshenko beam is less rigid than the Euler beam due to the large influence of rotational inertia and shear deformation.

Some researchers dealt with the moving graded beam as B. Li et al. [27] adopted on Timoshenko model and the principle of Hamilton to analyze the vibration equation of a moving graded beam and solved by the method of multi scales. The influences of an axially speed and stiffness on natural frequencies were examined.

Piovana and Sampaio [28], treated the axially moving elastic beam vibrations made of a material graded functionally in which the properties change according to the exponential law distribution. Euler's theorem was used to find the equation of motion which was solved by applying the element finite scalar method. The results show that fact, the damping is very reasonable when the beam is made only of metal and it has been heavily influenced by temperature. However, damping has a rare effect if the beam consists predominantly of structural ceramic substrates.

C. Ji et al. [29] established the equation of the axial movement of a graded nanobeam whose properties change based on the distribution of the power-law through the direction of the thickness. To find the equation of vibration that was resolved by the complex mode process, the Euler-Bernoulli theorem and the approach of Hamilton were used. The growth in the regression index of the material properties causes the drop in frequencies and wave velocity, although, in the case of a high in axial velocity, the natural frequencies and wave velocity increase appears and as shown in the results.

L. Q. Yao et al. [30], the equation of the axial movement of graded microbeam whose properties change by based on the distribution of the power-law through the direction of the thickness was created. The method of differential quadrate was used to address the vibration equations developed by the principle of Hamilton and the theory of Timoshenko. Raising the regression index of material property causes the drop in natural frequencies, while natural frequencies rise in the case of an increase in axial velocity as manifest in the results.

A. Shariati et al. [31], the vibration equation of the viscoelastic moving graded beam in which properties change axially based on exponential law distribution was derived according to Euler and Rayleigh models. The vibration equations were resolved by the Galerkin approach. The results explained that a low rotary inertia factor leads to make the structure more stable.

A. Melaibari et al. [32] studied the axial variable load acting on a functionally graded beam with simply support-fixed, fixed-fixed, simple support and cantilever end supports. By relying on the power-law of distribution, the properties of a graded beam vary during the direction of depth. Shear deformation Reddy model is adopted to find equations of motion by applying the precept of Hamilton. The method of the differential quadrate was used to resolve the vibration equations of this system. Several factors affecting the mode shape and the buckling load are discussed, including the type of load, gradient index of the material properties, end supports, and slenderness ratio.

By looking at the previous research that dealt with the moving beam issue, we did not find a researcher who has dealt with the subject of cracked moving beam except M. Sarigül [33] established the vibration equation of the axially moving beam that was exposed to multi crack by the Euler model. It evident from the results that the crack depth adversely affects the natural frequencies (meaning that the frequencies decrease when the cracking depth increases and vice versa), but when the axial velocity is too high, the crack depth influences will diminish.

After reviewing the previous literature, it was found that there is no researcher who has study a cracked graded beam with axial motion, so we attached great importance to this topic in this research paper. The cracked graded beam moving axially is studied. The gradient in material properties during the beam thickness was represented based on the law of power. The vibration equation is derived based on the Rayleigh model by applying the precept of Hamilton. The motion equation is solved using the Galerkin method. The effects of gradient index, axial speed, the depth of the crack, and the crack position on the vibration characteristics are illustrated.

\section{Theory}

Figure (1) clarified the cracked graded beam with axial motion. The axial and thickness axes illustrated by symbols $\mathrm{X}$ and $\mathrm{Z} . \mathrm{v}$ is the axial speed of a functionally graded (FG) beam. The graded beam is a mixture of ceramic and metal in the intermediate zone while the rich ceramic in the top zone and rich metal in the bottom zone. The length of a beam is $\mathrm{L}$ and the height of a beam is $h$. The crack parameters such as depth and position of the crack are given as a and $x_{c}$, respectively.
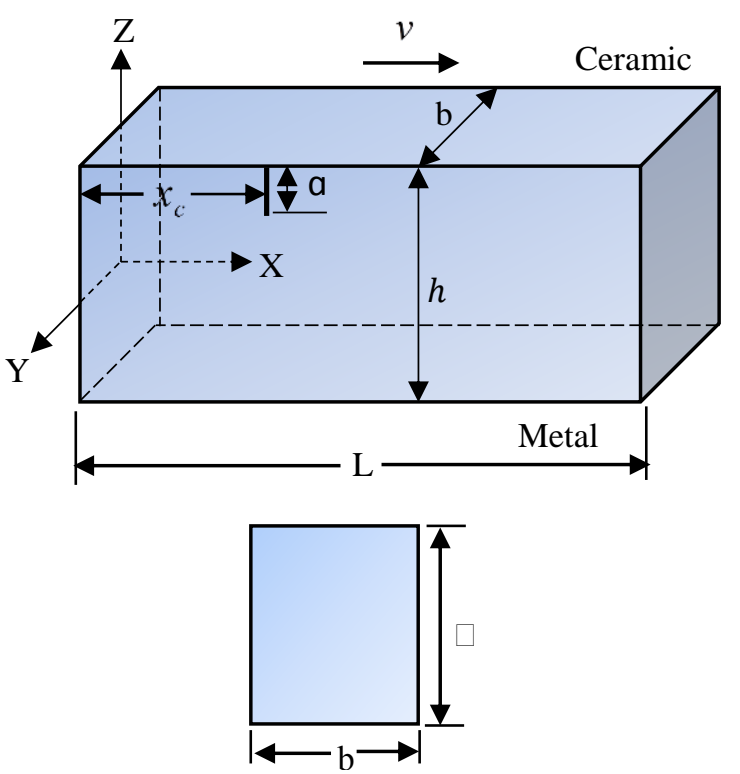
Fig. 1: Moving Graded Beam with Crack

The properties of the gradient materials differ during the thickness of the beam by relying on the law of power, and this material consists of two basic materials, namely metal and ceramic.

A volume fraction of a graded beam can be written as [34]:

$V_{t}=\left(\frac{z}{h}+\frac{1}{2}\right)^{p} \quad(0 \leq p \leq \infty)$

$V_{t}+V_{b}=1$

Where $\mathrm{z}$ is the mid-plane distance of the functionally graded beam $-\frac{h}{2} \leq z \leq \frac{h}{2},-\frac{h}{2}$ and $\frac{h}{2}$ represented the thickness of beam at top and bottom, respectively, while $\mathrm{p}$ is defined as the index of gradient. $V_{t}$ is the volume fraction at the top edge of the beam and $V_{b}$ is the volume fraction at the bottom edge of the beam.

The effective modulus of elasticity and effective density for power-law exponent are given as:

$$
\begin{aligned}
& E(z)=E_{t} V_{t}+E_{b} V_{b} \\
& \rho(z)=\rho_{t} V_{t}+\rho_{b} V_{b}
\end{aligned}
$$

Substation equations (1) \& (2) into equation (3), the equations of elasticity modulus and density become:

$$
\begin{aligned}
& E(z)=\left(E_{t}-E_{b}\right)\left(\frac{z}{h}+\frac{1}{2}\right)^{p}+E_{b} \\
& \rho(z)=\left(\rho_{t}-\rho_{b}\right)\left(\frac{z}{h}+\frac{1}{2}\right)^{p}+\rho_{b}
\end{aligned}
$$

The distance between middle plane and neutral plane is given as [35]:

$b_{o}=\frac{\int_{-h / 2}^{h / 2} z E(z) d z}{\int_{h / 2}^{h / 2} E(z) d z}=h \alpha \alpha_{1}$

Where

$$
\begin{aligned}
& \alpha=E_{\text {ratio }}-1 \\
& E_{\text {ratio }}=\frac{E_{c}}{E_{m}} \\
& \alpha_{1}=\frac{p}{2(2+p)(1+p+\alpha)}
\end{aligned}
$$

In which $E_{c}$ and $E_{m}$ are the modulus of elasticity of ceramics and metals, respectively.

Rayleigh graded beam's displacements can be written as [13]

$$
\begin{aligned}
& u_{1}(x, z, t)=-\left(z-b_{o}\right) \varphi(x, t) \\
& u_{2}(x, z, t)=w(x, t)
\end{aligned}
$$

Where $u_{1}(x, z, t)$ and $u_{2}(x, z, t)$ are axial and transverse displacements of beam, respectively.

The transverse displacement of middle plane is $w(x, t)$ while $\varphi(x, t)$ represent cross section rotation angle.

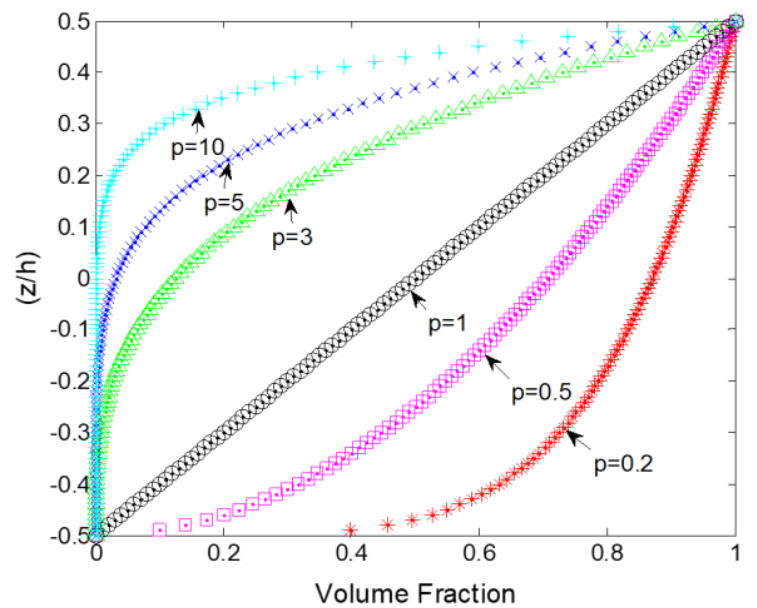

Fig. 2: Relationship between thickness direction and volume fraction of graded material properties.

The normal strain and stress of functionally graded Rayleigh beam are given as [29]

$$
\begin{aligned}
& \varepsilon_{x}=\frac{\partial u_{1}(x, z, t)}{\partial x}=-\left(z-b_{o}\right) \frac{\partial \varphi(x, t)}{\partial x} \\
& \sigma_{x}=E(z) \varepsilon_{x}=-E(z)\left(z-b_{o}\right) \frac{\partial \varphi(x, t)}{\partial x}
\end{aligned}
$$

In Rayleigh beam theory, $\varphi=\frac{\partial w}{\partial x}$

The potential energy due to bending of Rayleigh FGM beam is given as [30]: 


$$
\begin{aligned}
& P_{E}=\int_{0}^{l} \int_{A} \sigma_{x} \varepsilon_{x} d A d x=\int_{0}^{l} \int_{A} E(z)\left(z-b_{o}\right)^{2} \\
& \left(\frac{\partial^{2} w}{\partial x^{2}}\right)^{2} d A d x=I_{o} \int_{0}^{l} \frac{\partial^{4} w}{\partial x^{4}} d x
\end{aligned}
$$

Where

$$
I_{o}=\int_{A} E(z)\left(z-b_{o}\right)^{2} d A=E_{m} I \alpha_{2}
$$

In which

$$
\alpha_{2}=\frac{3 \alpha\left(2+p+p^{2}\right)}{(1+p)(2+p)(3+p)}-\frac{6 \alpha^{2} \alpha_{1} p}{(1+p)(2+p)}+1
$$

The second moment of inertia $I$ for rectangular crosssection can be given as $I=\frac{b h^{3}}{12}$

The variation of potential energy can be expressed by the following formula:

$\delta P_{E}=I_{o} \int_{0}^{l} \frac{\partial^{2} w}{\partial x^{2}} \frac{\partial^{2} \delta w}{\partial x^{2}} d x$

The kinetic energy of Rayleigh FGM beam theory is given as [13]

$$
\begin{aligned}
& K_{E}=\int_{0}^{l} \int_{A} \rho(z)\left(\frac{\partial w}{\partial t}+v \frac{\partial w}{\partial x}\right)^{2} d A d x \\
& +\int_{0}^{l} \int_{A} \rho(z)\left(z-z_{o}\right)^{2}\left(\frac{\partial^{2} w}{\partial x \partial t}+v \frac{\partial^{2} w}{\partial x^{2}}\right)^{2} d A d x \\
& =n_{1} \int_{0}^{l}\left(\frac{\partial^{2} w}{\partial t^{2}}+2 v \frac{\partial^{2} w}{\partial x \partial t}+v^{2} \frac{\partial^{2} w}{\partial x^{2}}\right) d x \\
& +n_{2} \int_{0}^{l}\left(\frac{\partial^{4} w}{\partial x^{2} \partial t^{2}}+2 v \frac{\partial^{4} w}{\partial x^{3} \partial t}+v^{2} \frac{\partial^{4} w}{\partial x^{4}}\right) d x
\end{aligned}
$$

Where

$$
\begin{aligned}
& n_{1}=\int_{A} \rho(z) d A=\rho_{m} A \alpha_{3} \\
& n_{2}=\int_{A} \rho(z)\left(z-b_{o}\right)^{2} d A=\rho_{m} I \alpha_{4}
\end{aligned}
$$

In which $A=b h, \mathrm{~A}$ is cross sectional area

$$
\alpha_{3}=\frac{1+p+\gamma}{1+p}
$$

$$
\alpha_{4}=1-\frac{6 \gamma^{2} \alpha_{1} p}{(1+p)(2+p)}+\frac{3 \gamma\left(2+p+p^{2}\right)}{(1+p)(2+p)(3+p)}
$$

Where

$$
\begin{aligned}
& \gamma=\rho_{\text {ratio }}-1, \\
& \rho_{\text {ratio }}=\frac{\rho_{c}}{\rho_{m}}
\end{aligned}
$$

Where $\rho_{c}$ is density of the ceramic and $\rho_{m}$ is density of the metal.

The kinetic energy variation can be expressed as

$$
\begin{aligned}
& \delta K_{E}=n_{1}\left|\begin{array}{l}
\frac{\partial w}{\partial t} \frac{\partial \delta w}{\partial t}+v \frac{\partial w}{\partial t} \frac{\partial \delta w}{\partial x}+v \frac{\partial w}{\partial x} \frac{\partial \delta w}{\partial t} \\
+v^{2} \frac{\partial w}{\partial x} \frac{\partial \delta w}{\partial x}
\end{array}\right| \\
& \left.+n_{2} \mid \begin{array}{l}
\frac{\partial^{2} w}{\partial x^{2}} \frac{\partial^{2} \delta w}{\partial t^{2}}+\frac{\partial^{2} w}{\partial t^{2}} \frac{\partial^{2} \delta w}{\partial x^{2}}+v \frac{\partial^{3} w}{\partial x^{3}} \frac{\partial \delta w}{\partial t} \\
+v \frac{\partial w}{\partial t} \frac{\partial^{3} \delta w}{\partial x^{3}}+v^{2} \frac{\partial^{2} w}{\partial x^{2}} \frac{\partial^{2} \delta w}{\partial x^{2}}
\end{array}\right)
\end{aligned}
$$

By applying Hamilton's principle which is given in the generic form as [36]

$\delta \int_{t_{1}}^{t_{2}}\left(P_{E}-K_{E}\right) d t=0$

Substituting the equations (13) and (20) into Hamilton's equation (21), integrating by parts and setting the coefficients of $\delta w=0$, the vibration equation of axially moving functionally graded Rayleigh beam is written as:

$$
\begin{aligned}
& \left(I_{o}-n_{2} v^{2}\right) \frac{\partial^{4} w}{\partial x^{4}}-2 v n_{2} \frac{\partial^{4} w}{\partial x^{3} \partial t}-n_{2} \frac{\partial^{4} w}{\partial x^{2} \partial t^{2}} \\
& +v^{2} n_{1} \frac{\partial^{2} w}{\partial x^{2}}+2 v n_{1} \frac{\partial^{2} w}{\partial x \partial t}+n_{1} \frac{\partial^{2} w}{\partial t^{2}}=0
\end{aligned}
$$

For dimensionless variables:

$$
\xi=\frac{x}{l}, \eta=\frac{w}{l}, V=v \sqrt{\frac{\rho_{m} A l^{2}}{E_{m} I}}, T=t \sqrt{\frac{E_{m} I}{\rho_{m} A l^{4}}}
$$


Substituting equation (22) into equation (21), the dimensionless motion equation of a moving graded Rayleigh beam can be given as:

$$
\begin{aligned}
& \left(\frac{\alpha_{2}}{\alpha_{3}}-\frac{\alpha_{r} \alpha_{4} V^{2}}{\alpha_{3}}\right) \frac{\partial^{4} \eta}{\partial \xi^{4}}+V^{2} \frac{\partial^{2} \eta}{\partial \xi^{2}}+2 V \\
& \left(1-\frac{\alpha_{r} \alpha_{4}}{\alpha_{3}} \frac{\partial^{2} \eta}{\partial \xi^{2}}\right) \frac{\partial^{2} \eta}{\partial \xi \partial T}+\left(1-\frac{\alpha_{r} \alpha_{4}}{\alpha_{3}} \frac{\partial^{2} \eta}{\partial \xi^{2}}\right) \\
& \frac{\partial^{2} \eta}{\partial T^{2}}=0
\end{aligned}
$$

Where $\alpha_{r}$ is rotation factor, can be present as $\alpha_{r}=\frac{I}{A l^{2}}$

\subsection{Boundary conditions}

The boundary conditions used in this paper are simply supported, and fixed-fixed, which are given in the dimensionless form as

1- Simply support

$$
\begin{aligned}
& \text { At } \xi=0, \eta(0)=\eta^{\prime \prime}(0)=0 \\
& \text { At } \xi=1, \eta(1)=\eta^{\prime \prime}(1)=0
\end{aligned}
$$

\section{2- Clamped-clamped}

$$
\begin{aligned}
& \text { At } \xi=0, \eta(0)=\eta^{\prime}(0)=0 \\
& \text { At } \xi=1, \eta(1)=\eta^{\prime}(1)=0
\end{aligned}
$$

\subsection{Crack modeling}

In order to examine the impact of the crack on the dynamic behavior of a functionally graded beam, the crack model has to be established adopting on fracture mechanics theorem. In the case of a beam cracking as shown in figure 1 , the beam is dividing into two segments. The crack is modeled as rotational spring as shown in figure 3 , the bending stiffness of the rotational spring can be expressed as [37]:

$$
K_{t}=\frac{1}{G}
$$

Where $G$ is the flexibility caused due to crack and can be derived by

$$
\frac{\left(1-v^{2}\right) S^{2}}{E(a)}=\frac{M^{2}}{2} \frac{d G}{d a}
$$

Where $\mathrm{S}$ is the stress intensity factor (SIF), $\mathrm{M}$ is the bending moment at the crack, and $E(a)$ is the elastic modulus at the crack tip, the stress intensity factor can be written as

$S=6 M \sqrt{\frac{\pi a \cdot f(z)}{b h^{2}}}$

By substituting eq. (28) into eq. (27), we get

$G=\int_{0}^{a} \frac{72 \pi\left(1-v^{2}\right) a \cdot f(z)}{b E(a) h^{2}} d a$

Where a represent the crack depth and $\mathrm{z}=\mathrm{a} / \mathrm{h}$ represent the crack depth ratio

After integral $\mathrm{G}$ and substituting it into equation (26), the compliance of the crack of a homogenous beam can be written as [38]:

$c=\frac{E I}{K_{t}}=6 \pi\left(1-v^{2}\right) h \cdot f(a / h)$

For a graded beam, the compliance of the crack can be written as [38]:

$c=\frac{I_{o}}{K_{t}}=6 \pi\left(1-v^{2}\right) h \cdot f(a / h) \cdot \alpha_{2}$

$\alpha_{2}$ is illustrated in equation (11).

Where $\mathrm{c}$ is depend on gradient index and crack depth ratio.

And the correct crack function $(\mathrm{f}(\mathrm{a} / \mathrm{h}))$ can be expressed as [38]:

$$
\begin{aligned}
& f(a / h)=0.6272(a / h)^{2}-1.04533(a / h)^{3} \\
& +4.5948(a / h)^{4}-9.9736(a / h)^{5}+20.2948 \\
& (a / h)^{6}-33.0351(a / h)^{7}+47.1063(a / h)^{8} \\
& -40.7556(a / h)^{9}+19.6(a / h)^{10}
\end{aligned}
$$

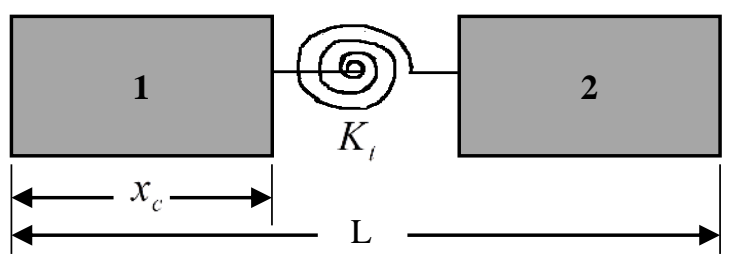


Fig. 3: Model of crack graded beam as rotational spring

After dividing the beam into two parts, the first part is integrated from 0 to $x_{c}$ while the second part is integrated from $x_{c}$ to L. Thus, the governing equations of cracked graded beam with axial motion are

$0 \leq x \leq x_{c}$

$\left(\frac{\alpha_{2}}{\alpha_{3}}-\frac{\alpha_{r} \alpha_{4} v^{2}}{\alpha_{3}}\right) \frac{\partial^{4} w_{1}}{\partial x^{4}}+v^{2} \frac{\partial^{2} w_{1}}{\partial x^{2}}$

$+2 v\left(1-\frac{\alpha_{r} \alpha_{4}}{\alpha_{3}} \frac{\partial^{2} w_{1}}{\partial x^{2}}\right) \frac{\partial^{2} w_{1}}{\partial x \partial t}$

$+\left(1-\frac{\alpha_{r} \alpha_{4}}{\alpha_{3}} \frac{\partial^{2} w_{1}}{\partial x^{2}}\right) \frac{\partial^{2} w_{1}}{\partial t^{2}}=0$

$x_{c} \leq x \leq l$

$\left(\frac{\alpha_{2}}{\alpha_{3}}-\frac{\alpha_{r} \alpha_{4} v^{2}}{\alpha_{3}}\right) \frac{\partial^{4} w_{2}}{\partial x^{4}}+v^{2} \frac{\partial^{2} w_{2}}{\partial x^{2}}$

$+2 v\left(1-\frac{\alpha_{r} \alpha_{4}}{\alpha_{3}} \frac{\partial^{2} w_{2}}{\partial x^{2}}\right) \frac{\partial^{2} w_{2}}{\partial x \partial t}$

$+\left(1-\frac{\alpha_{r} \alpha_{4}}{\alpha_{3}} \frac{\partial^{2} w_{2}}{\partial x^{2}}\right) \frac{\partial^{2} w_{2}}{\partial t^{2}}=0$

In the non-dimensional formula, the governing equations

$0 \leq \xi \leq \xi$

$$
\begin{aligned}
& \left(\frac{\alpha_{2}}{\alpha_{3}}-\frac{\alpha_{r} \alpha_{4} V^{2}}{\alpha_{3}}\right) \frac{\partial^{4} \eta_{1}}{\partial \xi^{4}}+V^{2} \frac{\partial^{2} \eta_{1}}{\partial \xi^{2}} \\
& +2 V\left(1-\frac{\alpha_{r} \alpha_{4}}{\alpha_{3}} \frac{\partial^{2} \eta_{1}}{\partial \xi^{2}}\right) \frac{\partial^{2} \eta_{1}}{\partial \xi \partial T} \\
& +\left(1-\frac{\alpha_{r} \alpha_{4}}{\alpha_{3}} \frac{\partial^{2} \eta_{1}}{\partial \xi^{2}}\right) \frac{\partial^{2} \eta_{1}}{\partial T^{2}}=0
\end{aligned}
$$

$\xi_{c} \leq \xi \leq 1$

$$
\begin{aligned}
& \left(\frac{\alpha_{2}}{\alpha_{3}}-\frac{\alpha_{r} \alpha_{4} V^{2}}{\alpha_{3}}\right) \frac{\partial^{4} \eta_{2}}{\partial \xi^{4}}+V^{2} \frac{\partial^{2} \eta_{2}}{\partial \xi^{2}} \\
& +2 V\left(1-\frac{\alpha_{r} \alpha_{4}}{\alpha_{3}} \frac{\partial^{2} \eta_{2}}{\partial \xi^{2}}\right) \frac{\partial^{2} \eta_{2}}{\partial \xi \partial T} \\
& +\left(1-\frac{\alpha_{r} \alpha_{4}}{\alpha_{3}} \frac{\partial^{2} \eta_{2}}{\partial \xi^{2}}\right) \frac{\partial^{2} \eta_{2}}{\partial T^{2}}=0
\end{aligned}
$$

\subsection{Solution Method}

In this paper, the Galerkin technique used to solve the vibration equations of a cracked graded Rayleigh beam. The general form of Galerkin technique is given as [31]:

$$
\eta(\xi, T)=\sum_{r=1}^{n} \phi_{r}(\xi) q_{r}(T)
$$

Where $\phi_{r}(\xi) q_{r}(T)$ and represents the shape function and generalized coordinates, respectively.

The mode shape function of the cracked FG beam can be expressed as the sum of the formation function of the un-cracked FG beam and the polynomial of $(\xi)$ :

$$
\begin{aligned}
& 0 \leq \xi \leq \xi_{c} \\
& \phi_{r 1}=\phi(\xi)+A_{o}+A_{1} \xi+A_{2} \xi^{2}+A_{3} \xi^{3} \\
& \xi_{c} \leq \xi \leq 1 \\
& \phi_{r 2}=\phi(\xi)+B_{o}+B_{1} \xi+B_{2} \xi^{2}+B_{3} \xi^{3}
\end{aligned}
$$

The continuity conditions and compatibility of the cracked graded beam at $\xi=\xi_{c}$ are given by

$$
\begin{aligned}
& \phi_{r 1}\left(\xi_{c}\right)=\phi_{r 2}\left(\xi_{c}\right) \\
& \phi_{r 1}^{\prime \prime}\left(\xi_{c}\right)=\phi_{r 2}^{\prime \prime}\left(\xi_{c}\right) \\
& \phi_{r 1}^{\prime \prime \prime}\left(\xi_{c}\right)=\phi_{r 2}^{\prime \prime \prime}\left(\xi_{c}\right) \\
& \phi_{r 2}^{\prime}\left(\xi_{c}\right)-\phi_{r 1}^{\prime}\left(\xi_{c}\right)=c \phi_{r 2}^{\prime \prime}\left(\xi_{c}\right)
\end{aligned}
$$

By coupling the boundary in equations (24) \& (25) and compatibility conditions in eq. (39) and equation (38), we get

\section{Pinned-pinned}

$\left(0 \leq \xi \leq \xi_{c}\right)$

$$
\phi_{r 1}=\phi(\xi)-\left(\frac{\xi_{c}-1}{\xi_{c}}\right)\left[c \xi_{c}(n \pi)^{2} \sin \left(n \pi \xi_{c}\right)\right] \xi
$$


$\left(\xi_{c} \leq \xi \leq 1\right)$

$\phi_{r 2}=\phi(\xi)+(1-\xi)\left[c \xi_{c}(n \pi)^{2} \sin \left(n \pi \xi_{c}\right)\right]$

2. Clamped-clamped

$\left(0 \leq \xi \leq \xi_{c}\right)$

$\phi_{r 1}=\left\{\begin{array}{l}\phi(\xi)-\phi(1)-\frac{c \phi^{\prime \prime}\left(\xi_{c}\right)+6 c \phi(1)-4 \phi^{\prime}(1)}{\left(1-2 c+6 c \xi_{c}\right)} \mid \\ \left(2-3 \xi_{c}\right) \xi^{2}-\frac{6 \phi^{\prime \prime}\left(\xi_{c}\right)+6 c \phi(1)-4 \phi^{\prime}(1)}{\left(1-2 c+6 c \xi_{c}\right)} \\ \left(2-2 \xi_{c}\right) \xi^{3}\end{array}\right]$

$\left(\xi_{c} \leq \xi \leq 1\right)$

$\phi_{r 2}=\left\{\begin{array}{l}\phi(\xi)-\phi(1)+\frac{c \phi^{\prime \prime}\left(\xi_{c}\right)+6 c \phi(1)-4 \phi^{\prime}(1)}{\left(1-2 c+6 c \xi_{c}\right)} \mid \\ (\xi-1)-\frac{c \phi^{\prime \prime}\left(\xi_{c}\right)+6 c \phi(1)-4 \phi^{\prime}(1)}{\left(1-2 c+6 c \xi_{c}\right)} \\ \left(2-3 \xi_{c}\right) \xi^{2}-\frac{6 \phi^{\prime \prime}\left(\xi_{c}\right)+6 c \phi(1)-4 \phi^{\prime}(1)}{\left(1-2 c+6 c \xi_{c}\right)} \mid\end{array}\right.$

By substituting equation (37) into equations (35) and (36), integration this equations and multiplying by $\phi_{s}$, the equation of motion in matrix form is given as

$[M] \ddot{q}+[C] \dot{q}+[K] q=0$

Where $[\mathrm{M}]$ is the mass matrix, $[\mathrm{C}]$ is the damping matrix, and $[\mathrm{K}]$ is the stiffness matrix of a cracked moving Rayleigh graded beam are given as:

$$
\begin{aligned}
& M_{r, s}=\int_{0}^{\xi_{c}}\left(\phi_{r 1}(\xi)-\frac{\alpha_{r} \alpha_{4}}{\alpha_{3}} \phi_{r 1}^{\prime \prime}(\xi)\right) \phi_{s 1}(\xi) d \xi \\
& +\int_{\xi_{c}}^{1}\left(\phi_{r 2}(\xi)-\frac{\alpha_{r} \alpha_{4}}{\alpha_{3}} \phi_{r 2}^{\prime \prime}(\xi)\right) \phi_{s 2}(\xi) d \xi
\end{aligned}
$$

$$
C_{r, s}=\int_{0}^{\xi_{c}}\left(2 V \phi_{r 1}^{\prime}(\xi)-2 V \frac{\alpha_{r} \alpha_{4}}{\alpha_{3}} \phi_{r 1}^{\prime \prime \prime}(\xi)\right) \phi_{s 1}(\xi)
$$

$d \xi+\int_{\xi_{c}}^{1}\left(2 V \phi_{r 2}^{\prime}(\xi)-2 V \frac{\alpha_{r} \alpha_{4}}{\alpha_{3}} \phi_{r 2}^{\prime \prime \prime}(\xi)\right) \phi_{s 2}(\xi) d \xi$

$$
\begin{aligned}
& K_{r, s}=\int_{0}^{\xi_{c}}\left(\frac{\alpha_{2}}{\alpha_{3}}-\frac{\alpha_{r} \alpha_{4} V^{2}}{\alpha_{3}}\right) \phi_{r 1}{ }^{(4)}(\xi) \phi_{s 1}(\xi) d \xi \\
& +\int_{0}^{\xi_{c}} V^{2} \phi_{r 1}^{\prime \prime}(\xi) \phi_{s 1}(\xi) d \xi \\
& +\int_{\xi_{c}}^{1}\left(\frac{\alpha_{2}}{\alpha_{3}}-\frac{\alpha_{r} \alpha_{4} V^{2}}{\alpha_{3}}\right) \phi_{r 2}{ }^{(4)}(\xi) \phi_{s 2}(\xi) d \xi \\
& +\int_{\xi_{c}}^{1} V^{2} \phi_{r 2}^{\prime \prime}(\xi) \phi_{s 2}(\xi) d \xi
\end{aligned}
$$

\subsection{Stability}

The differential equation of the second-order can be reduced to the differential equation of the first order, as [31]

$$
D \dot{Z}(T)+B Z(T)=0
$$

Where

$$
\begin{aligned}
& D=\left[\begin{array}{ll}
M & 0 \\
0 & C
\end{array}\right], B=\left[\begin{array}{cc}
-M & 0 \\
0 & K
\end{array}\right], \\
& Z(T)=\left\lceil\begin{array}{c}
q(T) \\
\dot{q}(T)
\end{array}\right]
\end{aligned}
$$

Assuming $Z(T)=Q e^{i \omega T}$ yields the following eigenvalue problem

$Y Q-i \omega J=0$

Where $\mathrm{J}$ indicates the unity matrix and $Y=-D^{-1} B$. Moreover, $\omega$ is the complex-valued natural frequency of a cracked moving FG Rayleigh beam.

\section{Results and discussion}

The beam used in this paper is made of functionally graded material that it is composed of ceramic and metal. Pure ceramic sits on the upper surface of the beam, while pure metal sits on the lower surface. The relevant parameters and the material properties are given as [34]: 
$\mathrm{L}=1 \mathrm{~m}, \mathrm{~b}=0.1 \mathrm{~m}, h=0.1 \mathrm{~m}$

Table 1 The graded material properties

\begin{tabular}{ccc}
\hline Material & Elasticity modulus & Density \\
\hline Steel & $210 \mathrm{GPa}$ & $7800 \mathrm{~kg} / \mathrm{m}^{3}$ \\
& & \\
\hline Alumina & $390 \mathrm{GPa}$ & $3960 \mathrm{~kg} / \mathrm{m}^{3}$ \\
& & \\
\hline
\end{tabular}

\subsection{Validation}

In this subsection, we will compare the results obtained through the equation (23) for Rayleigh graded intact beam at $\mathrm{V}=0, \mathrm{~L} / \mathrm{h}=100, E_{\text {ratio }}=\frac{E_{c}}{E_{m}}=4$, $\rho_{\text {ratio }}=\frac{\rho_{c}}{\rho_{m}}=1, \alpha_{r}=0$ with the results of Euler graded intact beam in ref. [39].

Table 2 Shows the comparison between the results (dimensionless natural frequency) of this study with the results of the Euler beam with different power index

\begin{tabular}{|c|c|c|c|c|c|}
\hline \multirow{2}{*}{$\omega_{\mathrm{i}}$} & \multirow{2}{*}{ Method } & \multicolumn{4}{|c|}{$\mathrm{P}$} \\
\hline & & 0 & 0.5 & 5 & 10 \\
\hline \multirow{3}{*}{$\omega_{1}$} & Present & 14.74 & 16.29 & 12.49 & 11.95 \\
\hline & Ref.[39] & 14.74 & 16.29 & 12.49 & 11.95 \\
\hline & Error & $0 \%$ & $0 \%$ & $0 \%$ & $0 \%$ \\
\hline \multirow{3}{*}{$\omega_{2}$} & Present & 78.94 & 65.17 & 49.96 & 47.79 \\
\hline & Ref.[39] & 78.94 & 65.17 & 49.96 & 47.79 \\
\hline & Error & $0 \%$ & $0 \%$ & $0 \%$ & $0 \%$ \\
\hline \multirow{3}{*}{$\omega_{3}$} & Present & 177.6 & 146.6 & 112.4 & 107.5 \\
\hline & Ref.[39] & 177.6 & 146.6 & 112.4 & 107.5 \\
\hline & Error & $0 \%$ & $0 \%$ & $0 \%$ & $0 \%$ \\
\hline
\end{tabular}

\subsection{Crack depth ratio impact $(\mathrm{a} / \mathrm{h})$}

The impact of the crack depth on three natural frequencies is illustrated in table 3 . The natural frequencies drop as the depth of crack increase. The percentage of the decreasing in the natural frequencies is $20.97 \%$ for simply supported and $12 \%$ for clampedclamped.
Table 3 dimensionless natural frequency with different crack depth ratio at $\delta=0.1, \mathrm{p}=1, \mathrm{u}=1, x_{c}=0.1$

\begin{tabular}{|c|c|c|c|}
\hline \multirow{2}{*}{$\mathrm{a} / \mathrm{h}$} & \multirow{2}{*}{$\Omega$} & \multicolumn{2}{|c|}{ Boundary conditions } \\
\hline & & Simply support & Clamped-clamped \\
\hline \multirow{3}{*}{0} & $\Omega 1$ & 12.9058 & 29.8538 \\
\hline & $\Omega 2$ & 52.7813 & 81.8489 \\
\hline & $\Omega 3$ & 118.0067 & 157.5196 \\
\hline \multirow{3}{*}{0.1} & $\Omega 1$ & 12.8884 & 29.6259 \\
\hline & $\Omega 2$ & 52.5382 & 81.7238 \\
\hline & $\Omega 3$ & 116.9730 & 157.5069 \\
\hline \multirow{3}{*}{0.3} & $\Omega 1$ & 12.7138 & 28.3073 \\
\hline & $\Omega 2$ & 50.5015 & 81.0284 \\
\hline & $\Omega 3$ & 109.4602 & 157.4657 \\
\hline \multirow{3}{*}{0.5} & $\Omega 1$ & 11.9178 & 26.6547 \\
\hline & $\Omega 2$ & 45.0100 & 80.2546 \\
\hline & $\Omega 3$ & 97.5487 & 157.4045 \\
\hline
\end{tabular}

\subsection{Crack position impact $\left(x_{c}\right)$}

The impact of a crack position along the beam on the three natural frequencies is examined in table 4. The rise in the location of crack causes a range of high and low natural frequencies.

Table 4 dimensionless natural frequency with different crack depth ratio at $\delta=0.1, \mathrm{p}=1, \mathrm{u}=1, \mathrm{a} / \mathrm{h}=0.2$

\begin{tabular}{|c|c|c|c|}
\hline \multirow{2}{*}{$x_{c}$} & \multirow{2}{*}{$\omega_{\mathrm{i}}$} & \multicolumn{2}{|c|}{ Boundary conditions } \\
\hline & & Simply support & Clamped-clamped \\
\hline \multirow{3}{*}{0} & $\omega_{1}$ & 12.9058 & 27.1684 \\
\hline & $\omega_{2}$ & 52.7812 & 75.4766 \\
\hline & $\omega_{3}$ & 118.0075 & 147.0692 \\
\hline \multirow{3}{*}{0.1} & $\omega_{1}$ & 12.8330 & 29.0621 \\
\hline & $\omega_{2}$ & 51.8208 & 81.4155 \\
\hline & $\omega_{3}$ & 114.0855 & 157.4928 \\
\hline
\end{tabular}




\begin{tabular}{llll}
\hline & $\omega_{1}$ & 12.4700 & 29.6544 \\
\cline { 2 - 4 } 0.3 & $\omega_{2}$ & 50.6040 & 78.5565 \\
\cline { 2 - 4 } & & & \\
\hline & $\omega_{3}$ & 117.5068 & 155.3742 \\
0.5 & $\omega_{1}$ & 12.2716 & 28.7680 \\
\cline { 2 - 4 } & $\omega_{2}$ & 52.7745 & 81.8434 \\
\cline { 2 - 4 } & $\omega_{3}$ & 112.8274 & 150.2547 \\
\hline
\end{tabular}

Figure 4 illustrates the influence of crack location on first and second frequencies ratios for clampedclamped end condition. Figure (a) realize that the maximum ratio of the first frequency at $\mathrm{xc}=0.225$ and $\mathrm{xc}=0.775$, but the minimum ratio in the end supports and the beam middle.

Also, we notice that the increases in the depth of crack causes decreases in the frequencies. The reason is due to the influence of the depth of crack on the beam stiffness, which decreases with the increase in the crack depth, which leads to a drop in the natural frequencies. In (4-b) the maximum second frequency ratio (natural frequency with crack/natural frequency without crack) at the beam middle, $\mathrm{xc}=0.175$ and $\mathrm{xc}=0.825$ while the minimum frequency ratio at the end supports.

Also, the crack depth impact on the natural frequency ratio is demonstrated. The ratio of the first and second frequencies decreases when the depth of crack increases because of the decrease of beam stiffness as a result of rise in the crack depth leads to decrease in the natural frequencies.

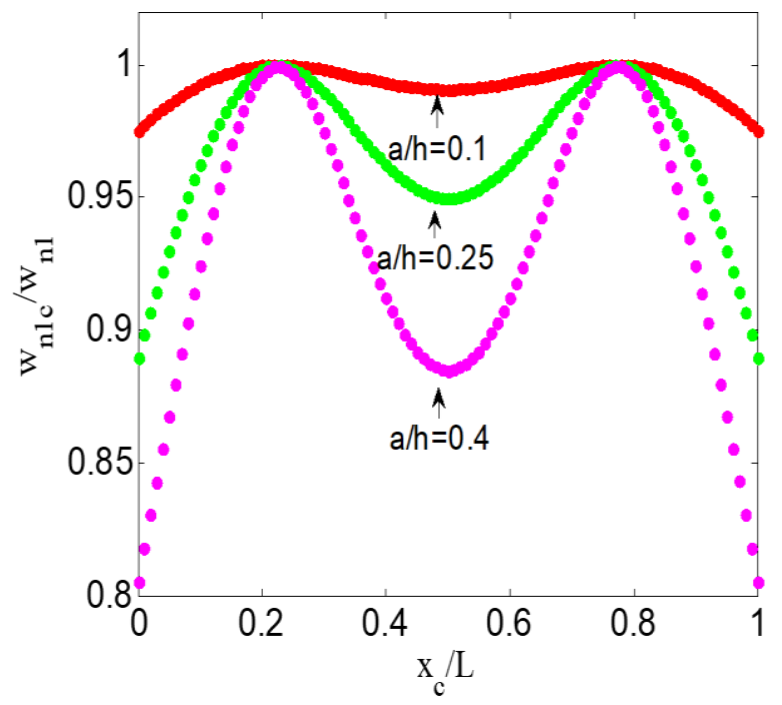

(a)

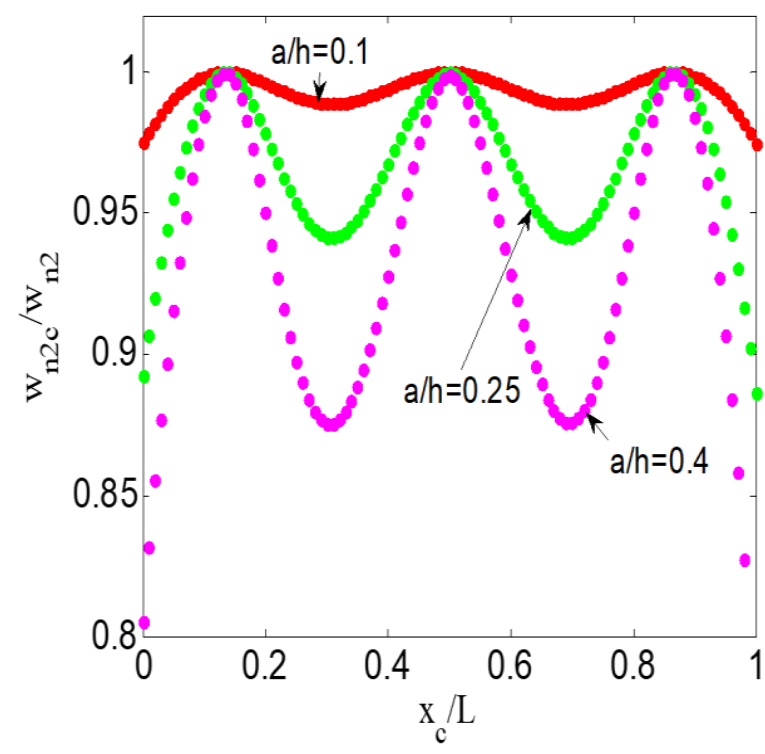

(b)

Figure 4 dimensionless natural frequencies ratio of cracked C-C FG beam verse dimensionless crack location at $\mathrm{u}=1, \delta=0.1, \mathrm{p}=1$

Figure 5 elucidate the relationship between the first and second frequency ratio (natural freqyenct with crack/ natural frequency without crack) and the crack location along the beam for simply supported end condition.

Fig. (5-a) clarified the first frequency ratio $\left(\omega_{n 1 c} / \omega_{n 1}\right)$ gradually decrease at increase the position of crack untile reaches to minmium frequency ratio at $\mathrm{xc}=0.5$ and then it goes back up to maxmium ratio in the beam end.

In (5-b) the maxmium second frequency ratio $\left(\omega_{n 2 c} / \omega_{n 2}\right)$ at the end supports and middle beam but the minmium ratio at $\mathrm{xc}=0.225$ and $\mathrm{xc}=0.775$ along the beam. Also, the natural frequency ratios decreases at the depth of crack increases for simply supported and clamped end conditions as clear in the two figures.

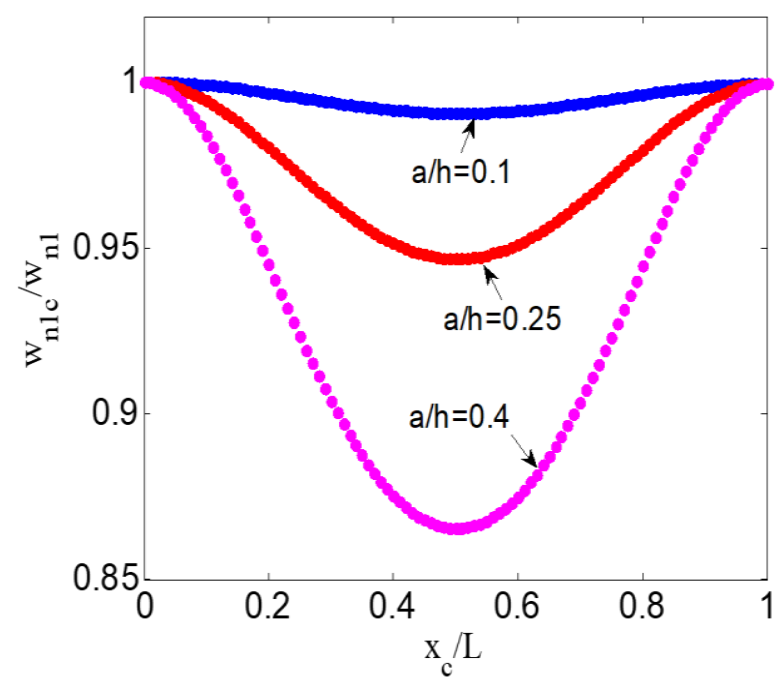

(a) 


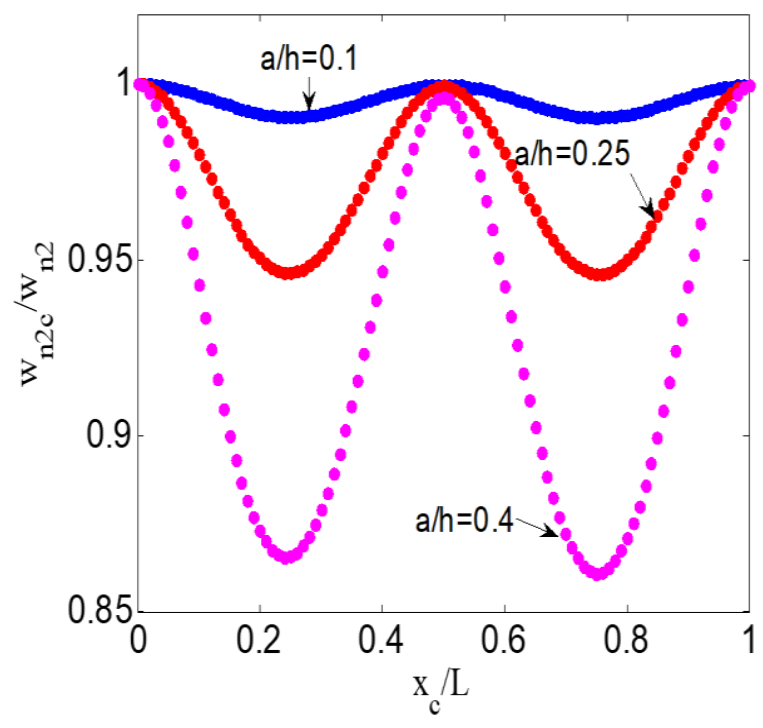

(b)

Figure 5 dimensionless natural frequencies ratio of cracked $\mathrm{S}-\mathrm{S}$ FG beam against crack location at $\mathrm{u}=1$, $\delta=0.1, \mathrm{p}=1$

Figures 6 and 7 show that the first and second frequency ratio (natural frequency with crack/natural frequency without crack) affected by the axial speed, the increase of the axial speed from 1 to 3 causes a drop in the ratio of natural frequencies for fixed-fixed and simply supported end conditions because the raising in the axial speed causes the lowering in the beam stiffness that leads to diminshe the natural frequency ratio.

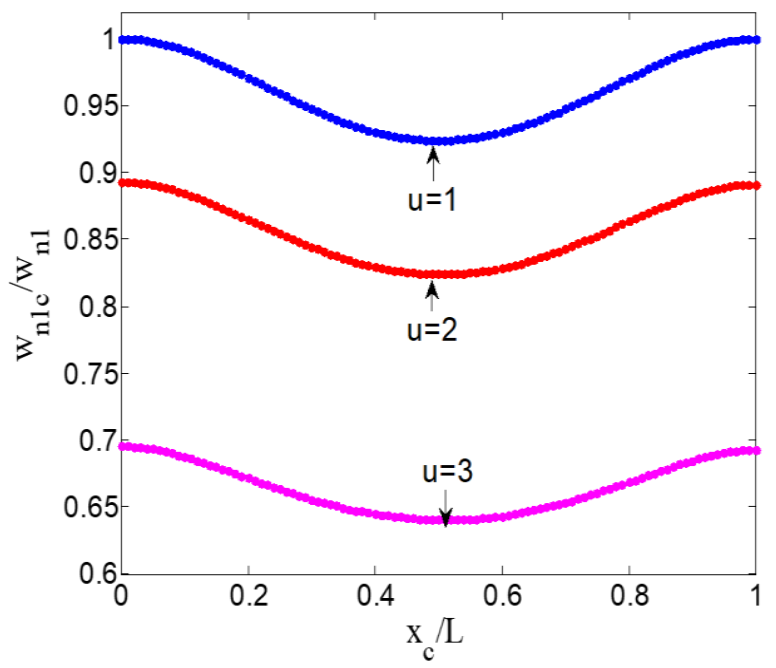

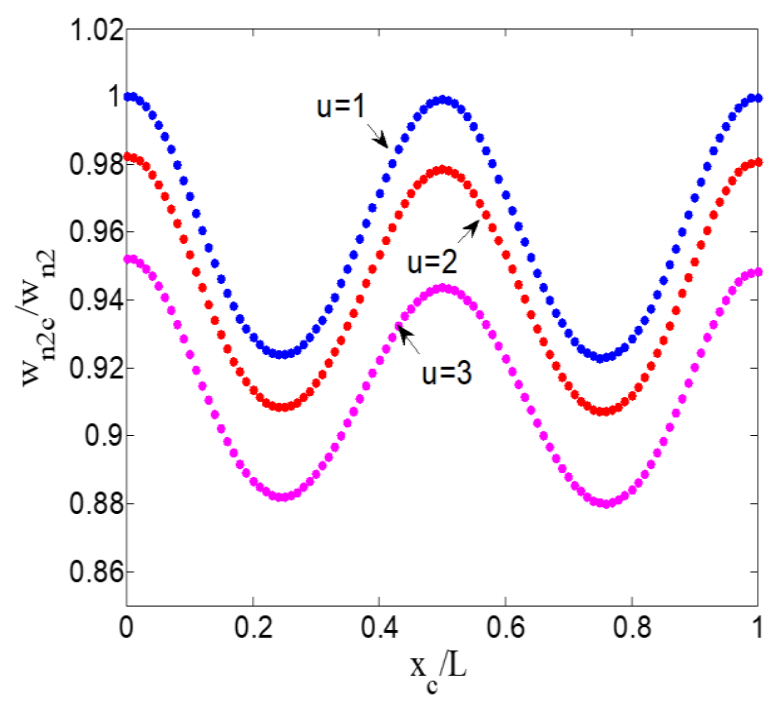

Figure 6 dimensionless natural frequencies ratio of cracked S-S FG beam at $\mathrm{L} / \mathrm{h}=10, \mathrm{a} / \mathrm{h}=0.3$
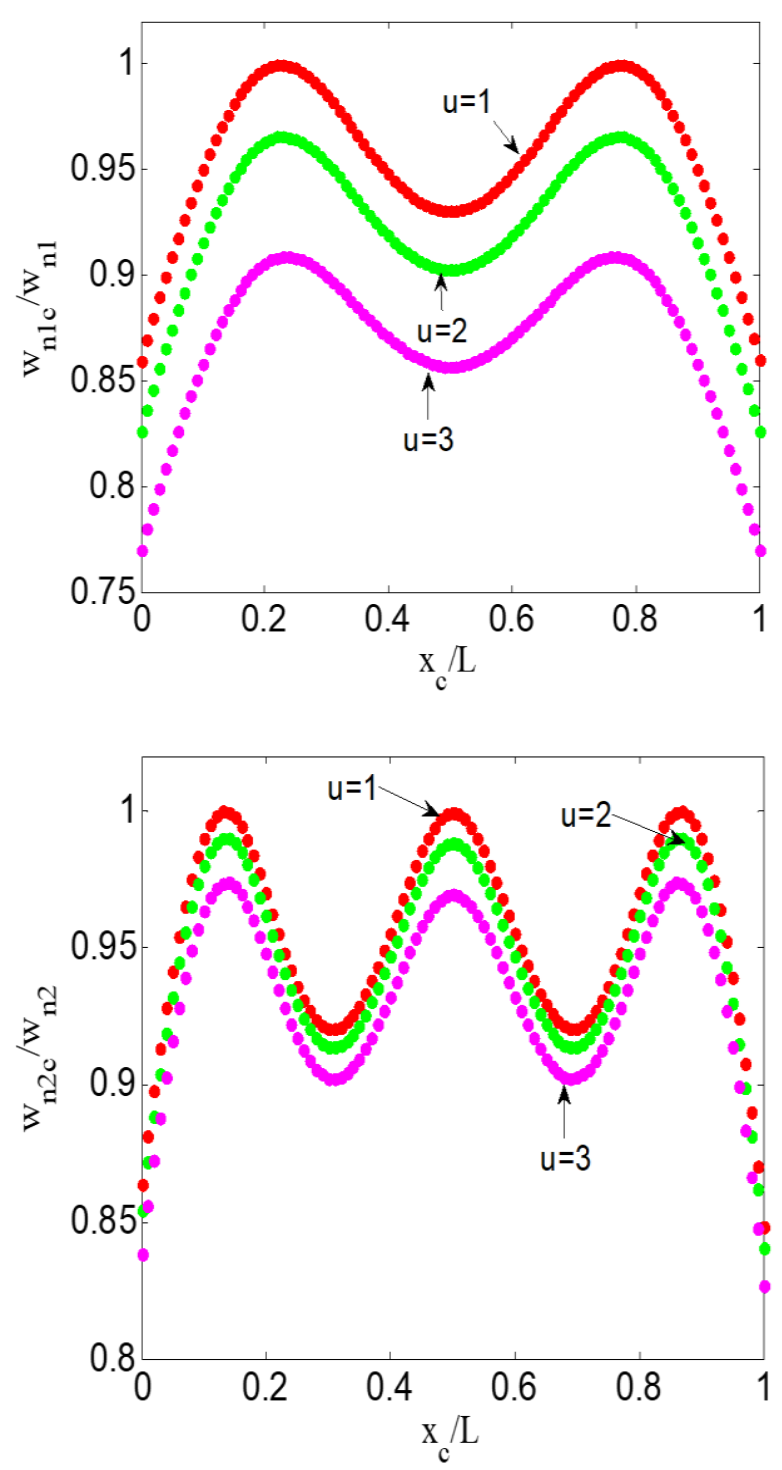
Figure 7 dimensionless natural frequencies ratio of $\mathrm{C}$ $\mathrm{C}$ cracked graded beam at $\mathrm{L} / \mathrm{h}=10, \mathrm{a} / \mathrm{h}=0.3$

Figures 8 and 9 show the relationship between the ratio of natural frequencies (the natural frequency with cracking to the natural frequency without cracking) and the crack position along the beam and for different values of the power index for two boundary condition such as simply supported and fixed-fixed. When the property power index increases from 1 to 10 , this leads to a decrease in the elastic modulus (i.e., an increase in metal components and a decrease in ceramic components) and the stiffness decreases as a result, and the beam becomes flexible, and thus the natural frequencies decreases.
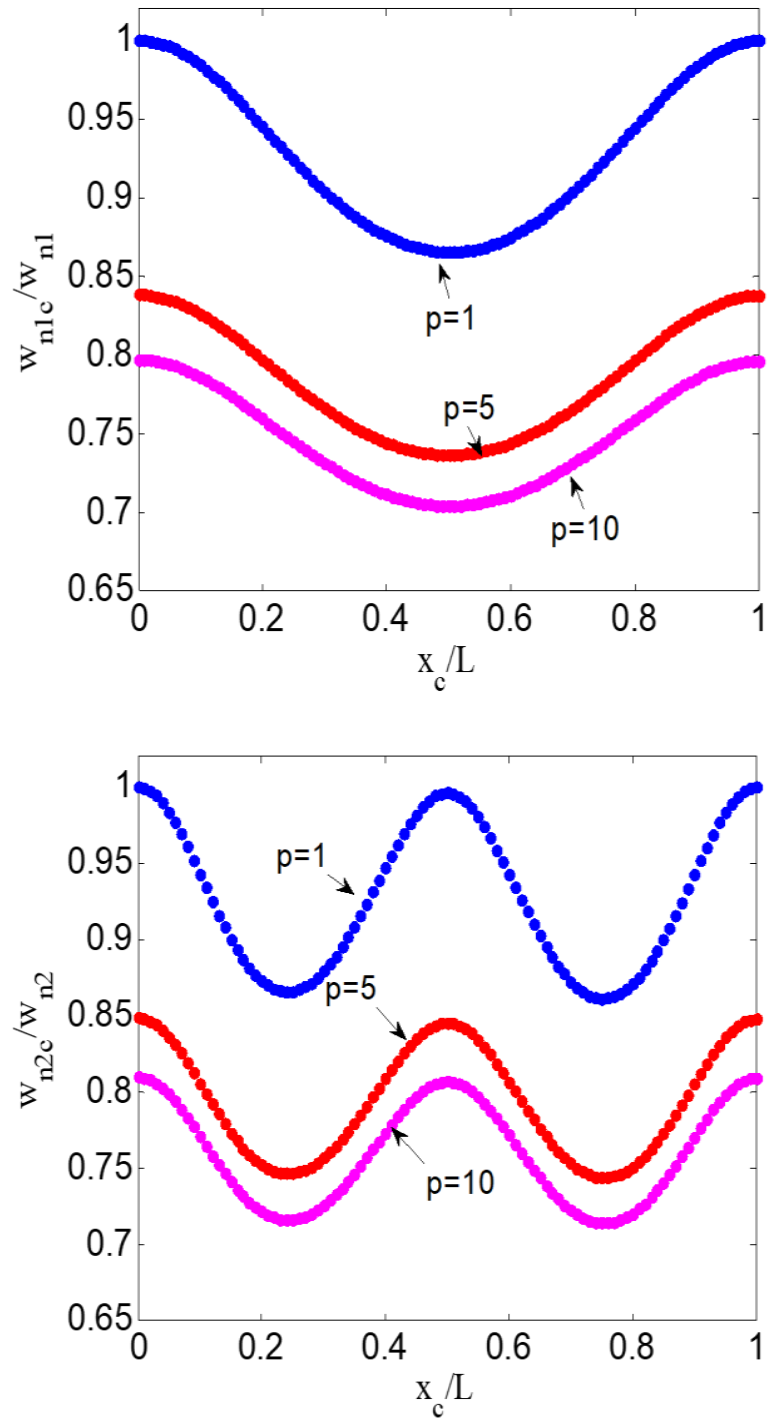

Figure 8 dimensionless natural frequencies ratio of cracked S-S FG beam at $\delta=0.1, \mathrm{u}=1, \mathrm{a} / \mathrm{h}=0.4$
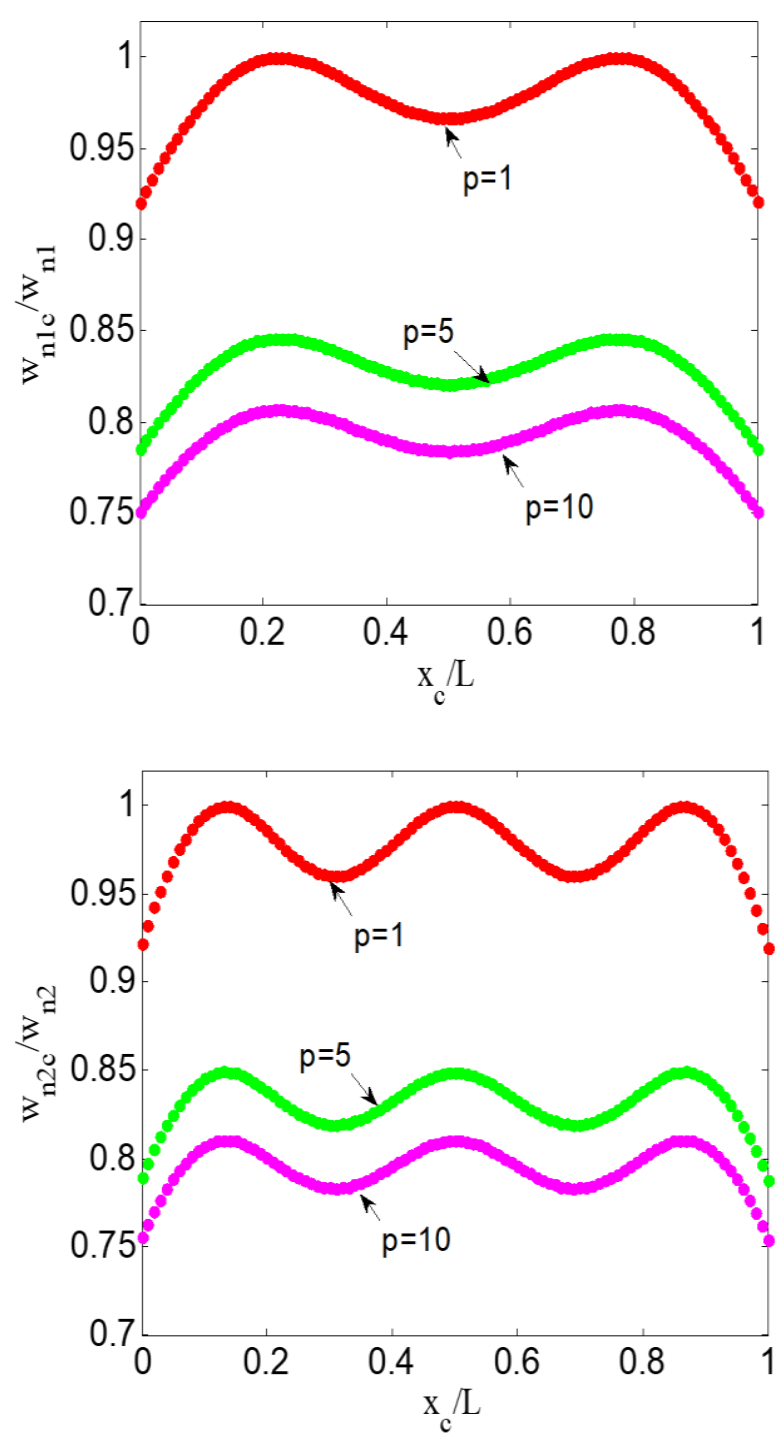

Fig. 9 dimensionless natural frequency ratio of C-C cracked graded beam at $\delta=0.1, \mathrm{u}=1, \mathrm{a} / \mathrm{h}=0.2$

\section{Conclusions}

Free vibration of a moving Rayleigh graded beam with crack is investigated. Galerkin's approach is used to analyze the equation of vibration of this system which is modeled by the principle of Hamilton. The depth and position of the crack, axial speed, and gradient property index influences on the characteristics of vibration are discussed. The main conclusions from the results of this study can summarize it as follows:

1. The first three natural frequencies decrease by increasing the axial velocity at a certain depth and location of the beam due to the impact of velocity on the stiffness of the beam, causing the beam to deflect, 
and thus the natural frequencies to decrease for simply supported and clamped-clamped end conditions.

2. The increase in the gradient index of the material properties causes natural frequencies dropping due to the fall in the elastic modulus, which makes the beam more flexible, which leads to natural frequencies reducing for simply supported and fixed-fixed end conditions.

3. When the crack depth raises, the beam stiffness decreases, and beam deflection occurs as a result, thus reducing the normal frequencies for fixed and simply supported end conditions.

\section{List of symbols}

L The length of the beam (m)

$\mathrm{b} \quad$ The width of the beam $(\mathrm{m})$

$h \quad$ The thickness of the beam (m)

a Crack depth (m)

$p \quad$ Power-law exponent

$\mathrm{v} \quad$ Velocity of a moving beam $(\mathrm{m} / \mathrm{s})$

$b_{o} \quad$ Distance of a middle \& neutral plane $(\mathrm{m})$

$x_{c} \quad$ Crack position (m)

A Area $\left(m^{2}\right)$

E $\quad$ Modulus of elasticity $\left(N / \mathrm{m}^{2}\right)$

$\rho \quad$ Density $\left(\mathrm{kg} / \mathrm{m}^{3}\right)$

$\alpha_{r} \quad$ Rotation factor

$P_{E} \quad$ Potential energy $(\mathrm{J})$

$K_{E} \quad$ Kinetic energy (J)

$V_{t} \quad$ Volume fraction at the beam top

$V_{b} \quad$ Volume fraction at the beam bottom

$\omega_{n} \quad$ Natural frequency of an intact beam ( $\left./ / \mathrm{s}\right)$

$\omega_{n c} \quad$ Natural frequency of a cracked beam (1/s)

\section{References}

[1] H. Ding and L. Q. Chen, "Galerkin methods for natural frequencies of high-speed axially moving beams," J. Sound Vib., vol. 329, no. 17, pp. 3484-3494, 2010, doi: 10.1016/j.jsv.2010.03.005.

[2] J. R. Chang, W. J. Lin, C. J. Huang, and S. T. Choi, "Vibration and stability of an axially moving Rayleigh beam," Appl. Math. Model., vol. 34 , no. 6 , pp. 1482-1497, 2010, doi: 10.1016/j.apm.2009.08.022.

[3] Y. Yesilce, "Determination of natural frequencies and mode shapes of axially moving timoshenko beams with different boundary conditions using differential transform method," Adv. Vib. Eng., vol. 12, no. 1, pp. 89-
108, 2013.

H. Y. Chen and H. B. Chen, "A research on the dynamic characteristics of axially moving Timoshenko beam with compressive load," $J$. Vibroengineering, vol. 16, no. 2, pp. 656-672, 2014.

[5] N. Liu, G. Yang, and B. Chen, "1412.

Transverse vibration analysis of an axially moving beam with lumped mass," $J$. Vibroengineering, vol. 16, no. 7, pp. 32093217, 2014.

[6] Z. Yang, W. Li, Z. Yang, and J. Zhang, "Natural Frequency Numerical Solution to an Axially Moving Timoshenko Beam on Fixed Supports," vol. 2, no. Icadme, pp. 903-907, 2015, doi: 10.2991/icadme-15.2015.172.

[7] R. Farshbaf Zinati, M. Rezaee, and S. Lotfan, "Nonlinear Vibration and Stability Analysis of Viscoelastic Rayleigh Beams Axially Moving on a Flexible Intermediate Support," Iran. J.

Sci. Technol. - Trans. Mech. Eng., vol. 44, no. 4, pp. 865-879, 2020, doi: 10.1007/s40997019-00305-z.

[8] H. Ding, M. Zhu, and L. Chen, "Dynamic stiffness method for free vibration of an axially moving beam with generalized boundary conditions," Appl. Math. Mech. (English Ed., vol. 40, no. 7, pp. 911-924, 2019, doi: 10.1007/s10483-019-2493-8.

[9] M. Avcar, "Free Vibration Analysis of Beams Considering Different Geometric Characteristics and Boundary Conditions," Int. J. Mech. Appl., vol. 4, no. 3, pp. 94-100, 2014, doi: 10.5923/j.mechanics.20140403.03.

[10] C. F. Lü, W. Q. Chen, R. Q. Xu, and C. W. Lim, "Semi-analytical elasticity solutions for bi-directional functionally graded beams," Int. J. Solids Struct., vol. 45, no. 1, pp. 258-275, 2008, doi: 10.1016/j.ijsolstr.2007.07.018.

[11] M. Şimşek and T. Kocatürk, "Free and forced vibration of a functionally graded beam subjected to a concentrated moving harmonic load," Compos. Struct., vol. 90, no. 4, pp. 465473, 2009, doi: 10.1016/j.compstruct.2009.04.024.

[12] K. K. Pradhan and S. Chakraverty, "Free vibration of Euler and Timoshenko functionally graded beams by Rayleigh-Ritz method," Compos. Part B Eng., vol. 51, pp. 175-184, 2013, doi:

10.1016/j.compositesb.2013.02.027.

[13] M. Avcar, H. Hazim, and A. Alwan, “10.24107-Ijeas.322884-320662.Pdf," vol. 9, no. 2, pp. 127-137, 2017.

[14] S. A. Sina, H. M. Navazi, and H. Haddadpour, "An analytical method for free vibration analysis of functionally graded beams," Mater. Des., vol. 30, no. 3, pp. 741-747, 2009, doi: 10.1016/j.matdes.2008.05.015.

[15] F. Q. Zhao and Z. M. Wang, "Vibration of deploying rectangular cross-sectional beam 
made of functionally graded materials," J. Low

Freq. Noise Vib. Act. Control, vol. 37, no. 4, pp. 748-761, 2018, doi:

10.1177/1461348418765957.

[16] M. Aydogdu and V. Taskin, "Free vibration analysis of functionally graded beams with simply supported edges," Mater. Des., vol. 28, no. 5, pp. 1651-1656, 2007, doi:

10.1016/j.matdes.2006.02.007.

[17] H. T. Thai and T. P. Vo, "Bending and free vibration of functionally graded beams using various higher-order shear deformation beam theories," Int. J. Mech. Sci., vol. 62, no. 1, pp. 57-66, 2012, doi:

10.1016/j.ijmecsci.2012.05.014.

[18] M. Şimşek, "Buckling of Timoshenko beams composed of two-dimensional functionally graded material (2D-FGM) having different boundary conditions," Compos. Struct., vol. 149, pp. 304-314, 2016, doi: 10.1016/j.compstruct.2016.04.034.

[19] M. H. Ghayesh, "Viscoelastic mechanics of Timoshenko functionally graded imperfect microbeams," Compos. Struct., vol. 225, no. May, p. 110974, 2019, doi: 10.1016/j.compstruct.2019.110974.

[20] A. E. Alshorbagy, M. A. Eltaher, and F. F. Mahmoud, "Free vibration characteristics of a functionally graded beam by finite element method," Appl. Math. Model., vol. 35, no. 1, pp. 412-425, 2011, doi: 10.1016/j.apm.2010.07.006.

[21] H. Deng and W. Cheng, "Dynamic characteristics analysis of bi-directional functionally graded Timoshenko beams," Compos. Struct., vol. 141, pp. 253-263, 2016, doi: 10.1016/j.compstruct.2016.01.051.

[22] Y. Liu, J. Xiao, and D. Shu, "Free vibration of exponential functionally graded beams with single delamination," Procedia Eng., vol. 75, pp. 164-168, 2014, doi: 10.1016/j.proeng.2013.11.041.

[23] T. Van Lien, N. T. Duc, and N. T. Khiem, "Free vibration analysis of multiple cracked functionally graded Timoshenko beams," Lat. Am. J. Solids Struct., vol. 14, no. 9, pp. 17521766, 2017, doi: 10.1590/1679-78253693.

[24] A. Banerjee, B. Panigrahi, and G. Pohit, "Crack modelling and detection in Timoshenko FGM beam under transverse vibration using frequency contour and response surface model with GA," Nondestruct. Test. Eval., vol. 31, no. 2, pp. 142-164, 2016, doi: 10.1080/10589759.2015.1071812.

[25] S. Kitipornchai, L. L. Ke, J. Yang, and Y. Xiang, "Nonlinear vibration of edge cracked functionally graded Timoshenko beams," $J$. Sound Vib., vol. 324, no. 3-5, pp. 962-982, 2009, doi: 10.1016/j.jsv.2009.02.023.

[26] A. S. J. Swamidas, X. Yang, and R. Seshadri, "Timoshenko and Euler Formulations," J. Eng.
Mech., vol. 130, no. November, pp. 12971308, 2004.

[27] B. Li, Y. Tang, and L. Chen, "Nonlinear free transverse vibrations of axially moving Timoshenko beams with two free ends," Sci. China Technol. Sci., vol. 54, no. 8, pp. 19661976, 2011, doi: 10.1007/s11431-011-4466-1.

[28] M. T. Piovan and R. Sampaio, "Vibrations of axially moving flexible beams made of functionally graded materials," Thin-Walled Struct., vol. 46, no. 2, pp. 112-121, 2008, doi: 10.1016/j.tws.2007.08.031.

[29] C. Ji, L. Yao, and C. Li, “Transverse Vibration and Wave Propagation of Functionally Graded Nanobeams with Axial Motion," J. Vib. Eng. Technol., vol. 8, no. 1, pp. 257-266, 2020, doi: 10.1007/s42417-019-00130-3.

[30] L. Q. Yao, C. J. Ji, J. P. Shen, and C. Li, "Free vibration and wave propagation of axially moving functionally graded Timoshenko microbeams," J. Brazilian Soc. Mech. Sci. Eng., vol. 42, no. 3, 2020, doi: 10.1007/s40430-020-2206-9.

[31] A. Shariati, D. won Jung, H. MohammadSedighi, K. K. Zur, M. Habibi, and M. Safa, "Stability and dynamics of viscoelastic moving rayleigh beams with an asymmetrical distribution of material parameters," Symmetry (Basel)., vol. 12, no. 4, pp. 1-23, 2020, doi: 10.3390/SYM12040586.

[32] A. Melaibari, R. M. Abo-bakr, S. A. Mohamed, and M. A. Eltaher, "Static stability of higher order functionally graded beam under variable axial load," Alexandria Eng. J., vol. 59, no. 3, pp. 1661-1675, 2020, doi: 10.1016/j.aej.2020.04.012.

[33] M. Sarigül, "Parametric vibrations of axially moving beams with multiple edge cracks," Int. J. Acoust. Vib., vol. 24, no. 2, pp. 241-252, 2019, doi: 10.20855/ijav.2019.24.21184.

[34] M. Şimşek and S. Cansiz, "Dynamics of elastically connected double-functionally graded beam systems with different boundary conditions under action of a moving harmonic load," Compos. Struct., vol. 94, no. 9, pp. 2861-2878, 2012, doi: 10.1016/j.compstruct.2012.03.016.

[35] H. Ziou, H. Guenfoud, and M. Guenfoud, "Numerical modelling of a Timoshenko FGM beam using the finite element method," Int. J. Struct. Eng., vol. 7, no. 3, pp. 239-261, 2016, doi: 10.1504/IJSTRUCTE.2016.077719.

[36] Anderson Soares and Simone dos Santos Hoefel, "Analysis of Rotatory Inertia and Shear Deformation on Transverse Vibration of Beams," An. do IX Congr. Nac. Eng. Mecânica, vol. 550, no. 1966, 2016, doi: 10.20906/cps/con-2016-1101.

[37] L. L. Ke, J. Yang, S. Kitipornchai, and Y. Xiang, "Flexural vibration and elastic buckling of a cracked timoshenko beam made of 
functionally graded materials," Mech. Adv. Mater. Struct., vol. 16, no. 6, pp. 488-502, 2009, doi: 10.1080/15376490902781175.

[38] T. Van Lien, N. T. Duc, and N. T. Khiem, "A New Form of Frequency Equation for Functionally Graded Timoshenko Beams with Arbitrary Number of Open Transverse Cracks," Iran. J. Sci. Technol. - Trans. Mech. Eng., vol. 43, no. February, pp. 235-250, 2019, doi: 10.1007/s40997-018-0152-2.

[39] S. R. Li, D. F. Cao, and Z. Q. Wan, "Bending solutions of FGM Timoshenko beams from those of the homogenous Euler-Bernoulli beams," Appl. Math. Model., vol. 37, no. 1011, pp. 7077-7085, 2013, doi: 10.1016/j.apm.2013.02.047. 